\title{
A NOÇÃO DE TRABALHADOR OU COLABORADOR NA GESTÃO DAS PEQUENAS EMPRESAS: UMA ANÁLISE CRÍTICA DA ADMINISTRAÇÃO DE RECURSOS HUMANOS À GESTÃO ESTRATÉGICA DE PESSOAS
}

Bruna Rizzi ${ }^{1}$

Anelise Rebelato Mozzato ${ }^{1}$

Denize Grzybovski ${ }^{1}$

${ }^{1}$ Universidade de Passo Fundo 


\section{A NOÇÃO DE TRABALHADOR OU COLABORADOR NA GESTÃO DAS PEQUENAS EMPRESAS: UMA ANÁLISE CRÍTICA DA ADMINISTRAÇÃO DE RECURSOS HUMANOS À GESTÃO ESTRATÉGICA DE PESSOAS}

Resumo: Este ensaio teórico tem como objetivo refletir sobre o avanço na área de administração de recursos humanos (ARH) à gestão estratégica de pessoas (GEP) nos conceitos e práticas organizacionais, sob a perspectiva das racionalidades instrumental e substantiva debatendo sobre a possibilidade (ou não) da transformação de um trabalhador passivo e obediente, para outro, ativo, colaborativo e respeitado na sua essência, tendo como escopo as pequenas empresas. A mesma reflexão se dá na "evolução" da denominação empregado para colaborador em detrimento da noção de trabalhador. Por mais notório que seja o avanço das práticas de gestão, questionam-se: não seriam práticas para realização de ações da própria racionalidade instrumental? Sob a lente da teoria crítica, o presente ensaio teórico amplia a compreensão das terminologias utilizadas na área de GEP, visando que o discurso compactue com a prática na gestão das pequenas empresas e viabilizando pensar outras racionalidades que não somente a instrumental.

Palavras-chave: Gestão estratégica de pessoas. Racionalidade instrumental. Racionalidade substantiva. Trabalhador.

\section{Proposições Iniciais: a teoria crítica orientando o debate}

Este ensaio teórico traz uma reflexão sobre o avanço da área administração de recursos humanos (ARH) nos conceitos e práticas organizacionais para uma abordagem da gestão estratégica de pessoas (GEP), sob a perspectiva das racionalidades instrumental e substantiva. Toma-se como escopo a pequena empresa. Dado o fato de que a racionalidade é utilizada para compreender como está sendo encaminhada a emancipação das pessoas (SOUTO; MAIOR, 1998), por mais notório que seja o avanço das práticas de gestão orientadas pela racionalidade instrumental em direção à racionalidade substantiva, questionam-se suas razões: não seriam práticas para realização de ações da própria racionalidade instrumental em todos os tipos organizacionais, exceto às pequenas empresas?

Diante desse e outros questionamentos, sob a lente da teoria crítica, propõe-se debater sobre a possibilidade (ou não) de transformação de um trabalhador passivo e obediente para outro, ativo, colaborativo e respeitado na sua essência nas práticas de gestão organizacional. A mesma reflexão se dá no sentido da "evolução" da denominação empregado para colaborador, bem como nas supostas transformações ocorridas nas práticas do departamento de pessoal sob o auspício da ARH e àqueles efetivamente seguidos na GEP.

Um dos argumentos é que o debate reside nos espaços de trabalho projetados para processos de trabalhos formatados e orientadores de práticas de gestores de empresas de médio e grande porte, contudo não são considerados válidos para a gestão das pequenas empresas. $\mathrm{Na}$ gestão de pequenas empresas, a improvisação, a colaboração espontânea na realização das diferentes tarefas e a necessidade de cada trabalhador assumir atividades sem esperar contrapartida está implícita no convívio entre proprietário e trabalhador sem distinção de hierarquia e outras particularidades inerentes a elas, como descrevem Cêra e Escrivão Filho 
(2003), Grossi e Oliveira Filho (2009), Crnkovic e Moretti (2012), Grzybovski (2016), Vogt e Bulgacov (2019) e Rosim, Escrivão Filho e Nagano (2019).

Justifica-se esse estudo em razão da necessidade de se buscar a articulação entre os anseios organizacionais competitivos (lógica instrumental) e a expectativa de emancipação do trabalhador (lógica substantiva), não se negando, assim como Guerreiro Ramos (1989) o fez, a possibilidade da coexistência de ambas, abrindo-se assim o espaço para o debate sobre o real interesse da GEP. A noção de real é tomada aqui na perspectiva da sociologia do conhecimento de forma que as reflexões decorrentes distanciam-se da multiplicidade empírica da noção de colaborador para se aproximar dos processos pelos quais ele socialmente foi estabelecido como realidade (BERGER; LUCKMANN, 2001).

Entende-se que assim se está avançando no debate tendo como pressuposto uma organização mais humanizada, colaborativa e cúmplice (POUTSMA et al., 2006). Dessa forma, o termo trabalhador parece mais apropriado aos propósitos do presente manuscrito do que a denominação empregado ou colaborador. Tais anseios, em uma perspectiva substantiva de emancipação do trabalhador, leva ao questionamento sobre a efetiva evolução e valorização do trabalhador ou se apenas é um discurso para a realização econômica de uma organização. Por conseguinte, não há indícios de que se está caminhando para uma neoescravidão?

Corrobora-se tanto com Marinho e Viera (2019) que recentemente versaram sobre a escravidão contemporânea, assim como com Aktouf(2001) quando salienta que há necessidade de compreensão das razões e circunstâncias que provocam essa metamorfose nas relações de trabalho. O movimento (por mais que ainda "tímido") em direção a maior humanização nas organizações não é um ideal romântico nem uma utopia, mas uma necessidade. Essas questões abrem campo para abordar o tema pela lente da teoria crítica, a qual oferece vias de reflexão consideradas mais adequadas na compreensão sobre como os gestores da área de ARH ou GEP agem, bem como para entender as implicações de suas práticas para as pessoas e para a sociedade de forma geral.

\section{A noção de trabalhador versus colaborador}

Observa-se nas organizações o predomínio de um discurso que afirma a superação do rígido modelo taylorismo-fordista de gestão da produção por um modelo toyotista, centrado no princípio da flexibilidade, no qual o trabalhador é encorajado a pensar pró-ativamente, a encontrar soluções antes que os problemas aconteçam, incorporando participação e trabalho em equipe (ALVES, 2001). Esse, por sua vez, foi superado pela concepção de um espaço de trabalho estruturado com base na flexibilidade, grupos autônomos de trabalho e enriquecimento de funções presente no volvismo (WOOD JR., 1992).

Considerando esse contexto é oportuno compreender o fenômeno organizacional da transformação metafórica de um trabalhador passivo e obediente para um outro mais ativo e colaborativo (AKTOUF, 2001). Assim, questiona-se: estamos diante de um processo de organização onde o empregador vê no empregado não bem um subordinado, mas sim, um colaborador? Parece que esse é o ponto de início do processo em que a noção de trabalhador começa a ser forjada na noção de colaborador, cujo contexto social legitimou e solidificou a nova denominação no mundo do trabalho.

O toyotismo tem seus protocolos institucionais voltados para captura da subjetividade do trabalhador pela lógica do capital (ALVES, 2001). Seus princípios organizacionais disseminaram-se pelo mundo capitalista nas décadas de 1980 e 1990 como um regime de 
acumulação flexível e um novo complexo de reestruturação produtiva (HARVEY, 1995). Visando a superação do modelo taylorismo-fordista, o toyotismo tem sua essência na busca do comprometimento estimulado do trabalho com um significado para além de sua origem sócio histórica e cultural, vinculada ao capitalismo japonês e que tenta se tornar um senso comum da produção de valor (ALVES, 2001). Dessa forma, a gestão do trabalho da organização objetiva e a participação dos trabalhadores também no planejamento das tarefas:

\begin{abstract}
a ideia de participação e corresponsabilização do trabalhador representou a quebra do ideário taylorista, que, embora valorizasse o envolvimento do trabalhador, limitava sua participação efetiva por meio de hierarquias rígidas e controle de tempos e movimentos que retiravam deste qualquer possibilidade de intervir no processo produtivo. O toyotismo, ao contrário, parte do reconhecimento de que o trabalhador é quem mais tem condições de intervir no sentido de eliminação de tempos mortos com ideias sobre como melhorar a organização da produção, evitando o retrabalho, incrementando a qualidade e a produtividade (LIMA, 2007, p. 44).
\end{abstract}

Em uma combinação de estratégias gerenciais e discursivas que demandam maior participação, envolvimento e responsabilização por parte dos trabalhadores, tem-se a disseminação de que quem vive a situação, sabe a melhor solução, caracterizando-se em um indicativo desse sistema de gestão sobre a subjetividade dos trabalhadores.

Alves (2001) destaca no toyotismo dispositivos organizacionais que sustentam a produção fluída e difusa, entre eles os programas de gerenciamento pela qualidade total, a produção just-in-time, o método Kanban, as novas formas de pagamento e de remuneração flexíveis e, principalmente, a difusão da terceirização. Soma-se a esses, novo vocabulário no mundo do trabalho com função psicossocial (ALVES, 2008). O autor destaca que, a troca da nomenclatura "operários" ou "empregados" por "colaboradores" não é inocente. O "criador" do toyotismo, Taichi Ohno, considera as empresas fornecedoras de "empresas colaboradoras", ocultando a relação de poder contido na relação de capital (ALVES, 2008). De fato, como afirma Gramsci (1984), o terreno ideológico que nasce com o toyotismo é também uma nova atitude psicológica que incentiva a afirmação da aparência das superestruturas.

A área de recursos humanos (ARH) no toyotismo ganha maior visibilidade, sendo considerado o "cérebro" da organização, enquanto as demais áreas são os "nervos" deste corpo de trabalho por interligar todos numa filosofia comum (coesão ideológica) do topo à base da estrutura organizacional (PINTO, 2012). Essa abordagem discorre que as organizações buscam pelo máximo engajamento da força de trabalho, o que é verificado de maneira muito peculiar no chamado "trabalho em equipe" e com o discurso que valoriza o individual, considerando o trabalhador como um colaborador. Nesse sentido, alguém que ontologicamente possui os mesmos valores da organização em detrimento da sociabilidade coletiva, colocando em prática discursos de valores coesos entre organização e seus subordinados.

As organizações adotam diretrizes trabalhistas institucionalizadas e, com isto, aproximam o trabalhador ocultando a relação entre empregado-empregador. $\mathrm{O}$ trabalhador passa a ser concebido como colaborador, cuja prática propõe desconsiderar a relação de poder existente na relação empregatícia e a organização espera que, quase de maneira dócil, que o trabalhador colabore com o sucesso organizacional, sob a justificativa que da mesma forma atingirá o sucesso pessoal (MUÇOUÇAH, 2013).

Como discute Pinto (2012), a gestão flexível proposta no modelo toyotista de gestão impõe aos trabalhadores alterações de seus costumes e de seus comportamentos mediante uma introjeção subjetiva de princípios de conduta moral. Configura-se, portanto, num sistema de 
gestão que constitui, além de uma metodologia de organização técnica do trabalho, um sistema de costumes e políticas com suas formulações práticas não apenas limitadas a uma forma específica de cooperação no trabalho, mas estruturadas na teocracia (PINTO, 2012), na qual os trabalhadores estão servindo à acumulação de capital da organização, já incitado no contexto do taylorismo-fordismo. Consequentemente, é um agir organizacional puramente na perspectiva da racionalidade instrumental, contemplando apenas as exigências do capital.

Nesse contexto, como ficam os anseios dos trabalhadores? Se tais anseios fossem considerados, os fundamentos da racionalidade substantiva também seriam pensados. É uma condição paradoxal da ARH (MUZZIO, 2014). Como refere o autor, se os anseios dos trabalhadores fossem de fato considerados na perspectiva emancipatória, a racionalidade substantiva deveria fazer parte e nela seria possível verificar a convergência das racionalidades instrumental e substantiva.

Muitas são as contradições no mundo do trabalho, ainda mais numa sociedade capitalista, na qual o lucro está na sua essência como finalidade única. Essa é a lógica da racionalidade instrumental. Por racionalidade instrumental entende-se a ação orientada para a otimização de resultados econômicos, com predomínio para normas e regras como os meios mais adequados para o alcance dos objetivos organizacionais (KALBERG, 1980). Tal modo de produção era visto como necessário, e não alienante, haja vista que se acreditava que no final todos ganhariam e os sacrifícios seriam recompensados (FURTADO, 1980). Seguindo essa lógica, como afirma Chanlat (1996), o culto as empresas (liberalismo econômico) atingiu o seu ápice nos anos 80 , trazendo consequências, como a difusão massiva das práticas de gestão e o aumento do número de estudantes em gestão. Dessa forma, buscou-se racionalizar todas as esferas da vida, instalando-se a cultura do management, a hegemonia do econômico.

Entretanto, como aponta Antunes (2015), essa lógica leva à precarização do trabalho e à exploração do trabalhador, mas mesmo assim torna-se o ideário empresarial da empresa flexível. Por conseguinte, estratégias de controle, explícitas ou implícitas são recorrentes e reconhecidas por todos como válidas no contexto do mundo do trabalho.

\title{
3 Regras implícitas nas estratégias de controle
}

As formas de controle e denominação não se associam exclusivamente a ações explícitas, ao contrário, destacam-se como estratégias de gestão voltadas para o "sequestro da subjetividade" do trabalhador (FARIA; MENEGHETTI, 2011, p. 46). A validade das práticas se dá pelo modelo toyotista de gestão, que disseminou a ideologia. Como sustentam Faria e Meneghetti (2011, p. 50), o sequestro da subjetividade consiste no fato de:

\begin{abstract}
apropriar-se, planejadamente, através de programas na área de gestão de pessoas, e de forma sub-reptícia, furtiva, às ocultas, da concepção de realidade que integra o domínio das atividades psíquicas, emocionais e afetivas dos sujeitos individuais ou coletivos que a compõem (trabalhadores, empregados) [...] O sequestro da percepção e da elaboração subjetiva priva os sujeitos de sua liberdade de se apropriar da realidade e de elaborar, organizar e sistematizar seu próprio saber, ficando à mercê dos saberes e valores produzidos e alimentados pela organização sequestradora.
\end{abstract}

A apropriação do "sequestro" é da elaboração subjetiva do sujeito (BÉHAR, 2019). Organizações contemporâneas desenvolvem práticas para controle dos trabalhadores construídas sobre pressupostos raramente evidenciados e lógicas implícitas que se impõem ao trabalhador por meio de regras, procedimentos e indicadores (GAULEJAC, 2005). A partir de 
instrumentos racionalizados de gestão, por meio de controles implícitos, as organizações promovem autonomia velada (BÉHAR, 2019), introduzem hábitos e ajustam comportamentos que facilitam o controle dos trabalhadores de acordo com os interesses organizacionais (GAULEJAC, 2005). Tal racionalidade é vista como limitada na visão de Guerreiro Ramos (1989) e, como tal, necessita ser reexaminada numa visão mais ampliada, pós-moderna, que não considere apenas o imperativo econômico.

No modelo toyotista, o papel ativo dos trabalhadores recebe importância, uma vez que se busca "mobilizar conhecimento, capacidades, atitudes e valores necessários para que os trabalhadores possam intervir na produção, não apenas produzindo, mas também agregando valor" (ALVES, 2014, p. 61). De fato, atribuir valor e compartilhar com os trabalhadores a responsabilidade pelos resultados da organização e pela elaboração de normas também é uma prática que gera a adesão e a proximidade, transmitindo a ideia de uma liberdade que parece ampliada e de alcance da maioria, num "mundo administrado" (ADORNO, 2008, p. 177).

Segundo Linhart (2014, p. 45) essa estratégia de participação ativa do trabalhador traz ansiedade e insegurança, pois estes "estão permanentemente preocupados com a ideia de nem sempre estar em condições de responder a elas" e sob tais condições, estes trabalhadores; "devem dar provas o tempo todo, demonstrar competência e empregabilidade, justificar sua presença, sobretudo por uma lógica comparativa" (LINHART, 2014, p. 51).

Nesse sentido, o valor individual está alinhado à capacidade individual de adaptação às necessidades organizacionais, empenhando-se para ações que resultem em benefícios organizacionais (FARIA; MENEGHETTI, 2007; ALVES, 2014; LINHART, 2014). Ao mesmo tempo, ter a sensação de pertencer (não ser apenas cumpridor de ordens) estimula os trabalhadores a dedicarem-se mais pelo sucesso ilusoriamente pessoal e efetivamente organizacional, uma vez que estão a serviço da da organização (GAULEJAC, 2007).

Este sentir-se pertencido transcende o corpo e a mente do trabalhador (ALVES, 2011), permitindo que estes sejam utilizados de acordo com a racionalidade instrumental. Sob tais circunstâncias, Alves (2011, p. 111), coloca que "a organização toyotista do trabalho capitalista possui uma densidade manipulatória de maior envergadura". Tais formas de trabalho, frequentemente trazem consigo a imagem de trabalho libertador, no qual as organizações passam a ideia de que estão cultivando sonhos, valores e expectativas dos colaboradores. Dado o exposto, surge o questionamento quanto a atual densidade manipulatória, mesmo que se tenha como pressuposto uma organização mais humanizada, como a preconizada pela teoria crítica.

Faria $(2007 ; 2009)$ refere que, na proposta multidisciplinar da teoria crítica, se faz necessário compreender as questões que afetam a vida das pessoas, valorizando-as enquanto indivíduos e no coletivo, acima dos interesses organizacionais. A teoria crítica está pautada na emancipação das pessoas, independentemente dos espaços sociais que ocupem (FARIA, 2004; MOZZATO; GRZYBOVSKI, 2013). Mozzato e Grzybovski (2013) defendem que, na busca primordial da humanização, o indivíduo deve assumir o seu papel organizacional e social nas organizações nas quais trabalham, para que seja visto/reconhecido como ator ativo da ciência e do mundo, ou seja, sujeito/trabalhador emancipado. Contudo, é preciso reconhecer que muitos discursos gerenciais têm poder de dominação e seduz de forma velada a realidade (ADORNO, 2008), tema explorado na seção que se segue. 


\section{Discurso e poder nas organizações}

Partindo do pressuposto que as práticas discursivas, segundo Foucault (1988), não são ocultas e sim orientadas por crenças, visões de mundo, ideologias, e essencialmente por poder, reitera-se a possibilidade da força do discurso mudar por si as relações sociais, econômicas e de poder na sociedade (FREITAS, 2011). Para Foucault (1988, p. 89), "o poder está em toda parte; não porque englobe tudo, e sim porque provém de todos os lugares". Dessa forma, o poder não possui identidade própria, mas multiplicidade de formas socialmente produzidas no cotidiado das organizações.

Foucault $(1988 ; 1993 ; 2007)$ também apresenta os mecanismos de poder disciplinar nas sociedades, o qual atua sobre os corpos individuais e se manifesta pelo enquadramento das individualidades em espaço possível de controle que facilita uma forma específica de normalização dos comportamentos e, por consequência, a mobilização da subjetividade dos trabalhadores e a produção de trabalhadores dóceis e socialmente úteis. Segundo a análise de Foucault (2007), os discursos são como construções de projetos políticos que determinam e classificam a ilegalidade, do crime e do patológico no âmbito destas e na extensão de toda sociedade. Isto é, tudo que é produzido como interdito e se manifesta como produto da objetivação do exercício do poder é o que constitui os sujeitos sociais.

Nesse sentido, com o surgimento do modelo organizacional toyotista, onde as estruturas organizacionais passam a ser em rede e os espaços de trabalho descentralizados, prevê-se no âmbito do discurso, maior participação dos trabalhadores nas atividades socioinstitucionais, com ressignificações para a cultura e comportamento das organizações (FREITAS, 2011). No entanto, mesmo assim permanece preservada lógicas exploratórias e alienantes praticadas pelas organizações em relação aos trabalhadores (BÉHAR, 2019).

Quando se considera o espaço de trabalho sinônimo de espaço de confinamento, por meio das práticas de gestão descritas no modelo taylorista, o discurso gerencial dirigido aos trabalhadores visa inseri-los/aloca-los em um espaço de trabalho moldado por regras disciplinares e controle sobre o corpo e pensamento de forma que cada ação possa ser controlada/vigiada do início ao fim do expediente de trabalho. A intenção era produzir o assujeitamento do trabalhador (OLTRAMARI, FRIDERICHS; GRZYBOVSKI, 2014) às condições sociais promovidas pela organização do trabalho fabril por meio de desenvolvimento sujeição comportamental à obediência.

A partir do momento em que as organizações articulam cenários de competição intensa entre os trabalhadores, o gerenciamento é uma nova ferramenta de poder que tem a finalidade de obter a adesão dos empregados às exigências da empresa. Nas palavras de Gaulejac (2014, p. 31), a gestão passa a atuar como uma ideologia:

que legitima uma abordagem instrumental, utilitarista e contábil das relações entre o homem e a sociedade. Sob uma aparência pragmática e racional, a gestão subentende uma representação do mundo que justifica a guerra econômica.

Por consequência, têm-se um ambiente instável e inseguro originado da competição e que ocasiona sentimentos de angústia e sofrimento aos trabalhadores (GAULEJAC, 2014). Este contexto possibilita que a ação gerencial se imponha à consciência e crenças individuais, com vistas a maior acumulação de capital para as organizações (BEHAR, 2019). Por sua vez, o modelo da competência apropriado e ressignificado pelos discursos provenientes dos gestores da ARH, quase como sinônimo de um sujeito empreendedor de si mesmo, provoca um ilusório 
sentimento de autonomia na atuação e é direcionado para atingimento dos resultados da organização (BÉHAR, 2019).

Nesse sentido, Zarifian (2003, p. 52) coloca que:

\begin{abstract}
a autonomia é definida: pelo contrário das normas. Ganha-se em autonomia pela diminuição das normas [...]. É uma verdadeira inversão de valores em relação à tradição taylorista; a diminuição das normas se torna algo benéfico, o que mostra, indiretamente, que os empregos com mais normas são, se não um mal, pelo menos uma situação pouco desejável e valorizada.
\end{abstract}

Da mesma forma, o modelo disciplinar da organização do trabalho abre espaço para a modulação da autorresponsabilização, para aquisição das habilidades, competências e conhecimentos que viabilizem a permanência na condição de empregabilidade e que emerge como exercício contínuo da autonomia do trabalhador. Attila (2012) indica a "formação" de um "novo sujeito", isto é, a constituição de novo processo de subjetivação. Implica dizer que as novas experiências histórico-culturais fazem o indivíduo sentir-se como tal a partir de dispositivos assujeitadores mais sutis e eficazes. Por outro lado, viabiliza o aparecimento de meios que permitem o aparecimento da fragilidade das novas formas de dominação.

Ainda, acredita-se que os discursos constroem subjetividades e organizam as relações de poder e de resistência nas organizações (FOUCAULT, 2005). Tendo o pensamento foucaultiano como uma verdade, assume-se que ao tratar o trabalhador como um colaborador, os gestores organizacionais estão adotando uma prática de gestão sútil de controle. Sutilmente, por meio de um adjetivo de tratamento conferido ao trabalhador no espaço de trabalho, estabelecem os limites de todas ações humanas. Entretanto, como salientam Rohm e Lopes (2015, p. 343) essa "nova" gestão de mundo, por mais que pareça eficaz, culmina em perversão, causando sofrimento ao trabalhador em razão da pressão contínua que os adoece. Então, até quando esse tipo de gestão continuará sendo proliferado?

O discurso empresarial do início desse século transfere a culpa pela falta de subordinação dos "colaboradores" para características das atuais gerações. Nessa lógica é que ainda os formados em cursos de Administração continuam reproduzindo discursos e práticas, seguindo o mainstream da literatura e da prática organizacional. Eis aí um dos dilemas da contemporaneidade (ROCHA-DE-OLIVEIRA; PICCININI; BITENCOURT, 2012), sem se negar outros dilemas que o trabalho enfrenta na sociedade contemporânea, a exemplo das constantes transformações, ainda mais aceleradas nesse momento da quarta revolução industrial (indústria 4.0). Visto que tal cenário envolve o olhar da Administração, sobretudo na perspectiva crítica, surgem questionamentos tais como: até quando a razão instrumental (MEDEIROS; SOUZA, 2011) sustentará a racionalidade instrumental, sem abrir a possibilidade a outras racionalidades? Até quando a pessoa que trabalha (o trabalhador) terá que ser chamada de colaborador para mascarar um ideário neoliberal?

\title{
5 Reflexões finais
}

Neste ensaio foi apresentada uma evolução das noções de colaborador e trabalhador e práticas da ARH para GEP, objetivando colocar o trabalhador no centro do debate organizacional, não mais concebido apenas como um recurso a serviço da organização (racionalidade instrumental), mas como um ser humano respeitado na sua essência, com a sua subjetividade (racionalidade substantiva). Ao se considerar a necessidade de evolução na racionalidade e a coexistência das racionalidades nas organizações, mesmo com suas 
contradições e tensões, não haverá mais a necessidade de discursos "mascarados", possibilitando que o trabalhador seja concebido como tal, ciente de que está tanto a serviço do capital quanto das suas próprias convicções e responsabilidades.

Historicamente o departamento de pessoal isoladamente torna-se obsoleto e a GEP ganha espaço. A ARH ou mesmo a GP, podem ser categorizadas sob a perspectiva da racionalidade instrumental ao contemplar as exigências de competitividade organizacional, reduzindo o humano à condição simples de recurso. Por outro lado, a racionalidade substantiva considera a autorrealização, a emancipação e a autonomia do trabalhador (MUZZIO, 2014). De forma semelhante, relaciona-se ao avanço para a GEP, quando não ocorre apenas no nível do discurso como estratégia de controle.

As mudanças no mundo do trabalho e no contexto social-econômico gerou tensões na racionalidade instrumental, pressionando a necessidade de outras racionalidades. Nesse contexto, os conceitos de GP e GEP surgem alinhados às estratégias organizacionais (MARRAS, 2011) de grandes empresas que possuem processos desenhados e formatados, de forma que o trabalhador se apresenta ao trabalho como mais uma ferramenta de execução.

Numa visão mais crítica, voltada para a racionalidade substantiva, sobretudo na concepção da GEP, se observa que na gestão das pequenas empresas a lógica orientativa das práticas na área de GEP é da racionalidade substantiva. Os argumentos residem nas especificidades que a cercam, dentre as quais destacam-se espaços de trabalho menores e convivência e interações sociais cotidianas, cujas regras de comportamento são explícitas, sem discursos manipulativos em estruturas organizacionais mais orgânicas do que mecânicas. Por conseguinte, a emancipação do trabalhador é uma consequência da sua presença-ausência no referido espaço de trabalho.

Em consonância com a evolução da área de ARH para GEP, é preciso avaliar criticamente as mudanças que estão sendo produzidas neste cenário, considerando também o porte das organizações em análise e quais consequências produzem na vida dos trabalhadores e da sociedade como um todo. É oportuno questionar e compreender o fenômeno organizacional da transformação metafórica de um trabalhador passivo e obediente para um outro ativo, colaborativo e autônomo (AKTOUF, 2001), sem ignorar as questões de contexto e as especificidades que envolvem o porte das organizações.

Nessa lógica, o termo operário/empregado/funcionário está associado ao modelo taylorista-fordista de gestão, cuja proposição formal está na descrição de funções/departamentos (visão instrumental), mas também está relacionado à realidade socialmente construída. Tal entendimento pode deslocar o debate do campo teórico da Administração para o da Sociologia do Conhecimento, o qual é capaz de desvelar as nuances que separam o real da realidade (BERGER; LUCKMANN, 2001). Os processos de comunicação e cooperação organizacional levam a substituição do termo operário/empregado/funcionário pelo colaborador, onde estes últimos são vistos como participantes ativos na organização, essas voltadas para programas de qualidade e eficiência. Assim, discursos alienantes que definem a empresa como uma família, ou sob o apelo institucional de "vestir a camiseta", buscam desenhar um novo modelo de relação que concebe o empregado (passivo-obediente) um colaborador (cúmplice-ativo) (AKTOUF, 2001).

Este ensaio expôs o curso da ARH até alcançar a GEP até o momento atual e, em paralelo, uma análise da evolução dos termos operários/empregados/funcionário até "romântico" colaborador, para assim repensar um termo mais apropriado para a pós- 
modernidade, o trabalhador. Espera-se, assim, ampliar a compreensão real dos termos aplicados, viabilizando um debate necessário para que se possa trabalhar nas organizações com práticas de GEP mais humanizadoras. Deste modo, não ficando a serviço da chamada "escravidão contemporânea" (MARINHO; VIEIRA, 2019).

Entretanto, como referem Rosa e Alcadipani (2013, p. 208), "se queremos ampliar nossa capacidade de enxergar as organizações de um ponto de vista crítico, é preciso que esta crítica incida sobre a nossa própria forma de olhar". Haja visto que a teoria crítica busca questionar a realidade aparente, torna-se um dos caminhos possíveis na direção de uma sociedade melhor e mais justa (MOZZATO; GRZYBOVSKI, 2013). Como "o homem e a organização são elementos indissociáveis, espera-se uma relação que possibilite, cada vez mais, a convergência de visões que leve à plenitude do alcance dos propósitos desses dois elementos" (MUZZIO, 2014, p.715).

Espera-se que este ensaio teórico possa despertar em pesquisadores e leitores do meio empresarial um olhar diferente e crítico para a GEP e a gestão organizacional, considerando o trabalhador como um ser humano e não como um mero recurso, e ainda, que a organização possa ser percebida como uma instituição social e não com finalidade estritamente econômica. Chegando ao final desse trabalho também se tem como expectativa ampliar a compreensão das terminologias utilizadas na área de GEP, visando que o discurso realmente compactue com a prática, viabilizando outras racionalidades que não somente a instrumental, as quais de fato se constituam em alternativas mais humanizadoras nas práticas de gestão de pessoas nas organizações. Desta maneira vislumbra-se promover um olhar responsável sobre o trabalhador, pois só assim se pode pensar em uma GEP sensata dentro da área da Administração. Por fim, cabe salientar que, em razão da profundidade da análise, não se tem como pretensão findar o debate, mas incitá-lo.

\section{Referências}

ADORNO, T. W. As estrelas descem à terra: a coluna de astrologia do Los Angeles Times: um estudo sobre superstição secundária. São Paulo: UNESP, 2008.

AKTOUF, O. Administração e teorias das organizações contemporâneas: rumo a um humanismo radical? Organizações \& Sociedade, v. 21, n. 8, p. 13-33, 2001.

ALVES, G. Toyotismo como ideologia orgânica da produção capitalista. Organizações e Democracia, Marília, n. 1, p. 3-15, 2001.

ALVES, G. A subjetividade às avessas: toyotismo e "captura" da subjetividade do trabalho pelo capital. Cadernos de Psicologia Social do Trabalho, v. 11, n. 2, p. 223-239, 2008.

ALVES, G. Trabalho e subjetividade: o espírito do toyotismo na era do capitalismo manipulatório. São Paulo: Boitempo, 2014.

ANTUNES, R. A sociedade da terceirização total. Revista da ABET, v. 14, n. 1, 2015.

ATTILA M.; BARBOSA S.; MARTINS A. Da disciplina ao controle: novos processos de subjetivação no mundo do trabalho. Política \& Sociedade, v. 11, n. 22, 2012. 
BÉHAR, A. H. Meritocracia enquanto ferramenta da ideologia gerencialista na captura da subjetividade e individualização das relações de trabalho: uma reflexão crítica. Organizações \& Sociedade, v. 28, n 89, 2019.

BERGER, P. L.; LUCKMANN, T. A construção social da realidade. Ed. 20. Petrópolis: Vozes, 2001.

CÊRA, K.; ESCRIVÃO FILHO, E. Particularidades de gestão da pequena empresa: condicionantes ambientais, organizacionais e comportamentais do dirigente. In: EGEPE, 3, 2003, Brasília. Anais... Brasília: UEM/UEL/UnB, 2003, p. 796-812.

CHANLAT, J. F. Ciências Sociais e Management. São Paulo: Atlas, 1996.

CRNKOVIC, L. H.; MORETTI, S. L. A. Gestão de micro e pequenas empresas: uma proposta de disciplina para a formação do engenheiro. Gestão da Produção, Operações e Sistemas, v. 7, n. 4, p. 11-24, out-dez/2012.

DEJOURS, C. Trabalho vivo: trabalho e emancipação. Brasília: Paralelo, 2012.

FARIA, J. H., MENEGUETTI, F. K. Dissimulações discursivas e violência no trabalho. Curitiba: EPPEO, 2011.

FARIA, J. H. Economia política do poder: as práticas do controle nas organizações. Curitiba: Juruá, 2004.

FARIA, J. H. Análise crítica das teorias e práticas organizacionais. São Paulo: Atlas, 2007.

FARIA, J. H. Teoria crítica em estudos organizacionais no Brasil: o estado da arte. Cadernos EBAPE.BR, v. 7, n. 3, p. 509-515, 2009.

FREITAS, E. C. Cultura, linguagem e trabalho: Comunicação e discurso nas organizações, Revista Desenredo, v. 7, n. 1, p. 104-126, jan./jun. 2011.

FOUCAULT, M. História da sexualidade: a vontade de saber. Rio de Janeiro: Graal, 1988.

Microfísica do poder. Rio de Janeiro: Graal, 1993.

A verdade e as formas jurídicas. Rio de janeiro: Nau, 2005.

Vigiar e punir: história da violência nas prisões. Petrópolis: Vozes, 2007.

FURTADO, C. Pequena introdução ao desenvolvimento: enfoque interdisciplinar. São Paulo: Nacional, 1980. 
GAULEJAC, V. A gestão como doença social: ideologia, poder gerencialista e fragmentação social. São Paulo: Ideias e Letras, 2005.

GUERREIRO RAMOS, A. A nova ciência das organizações: uma reconceituação da riqueza das nações. Rio de Janeiro: FGV, 1989.

GROSSI, R.; OLIVEIRA FILHO, J. B. As particularidades das pequenas empresas sob a ótica do empreendedorismo e da teoria do processo de formação das estratégias. In: ENCONTRO DA ANPAD, 33, 2009, São Paulo. Anais do... São Paulo: Anpad, 2009.

GRZYBOVSKI, D. Empreendedorismo e gestão de pequenas empresas: uma contribuição do Egepe 2016. Revista Gestão \& Planejamento, v. 17, n. 2, p. 296-297, 2016.

HARVEY, D. A condição pós-moderna: uma pesquisa sobre as origens da mudança cultural. São Paulo: Loyola, 1995.

KALBERG, S. Max Weber's types of rationality: cornerstones for the analysis of rationalization process in history. American Journal of Sociology, v. 85, n. 5, p. 1145-1179, 1980.

LIMA, J. C. Do assalariamento e suas variações: do trabalho típico ao atípico. In: BORSOI (Org.). Velhos trabalhos, novos dias: modos atuais de inserção de antigas atividades laborais. Fortaleza/São Carlos: UFC/EdUFSCar, 2007. p. 33-53

LINHART, D. Modernização e precarização da vida no trabalho. In: ANTUNES, R. (Org.). Riqueza e miséria do trabalho no Brasil III. São Paulo: Boitempo, 2014.

MARINHO, M. O.; VIEIRA, F. O. A jornada exaustiva e a escravidão contemporânea, Cadernos EBAPE.BR, v. 17, n. 2, p. 352-361, 2019.

MARRAS, J. P. Administração de recursos humanos: do operacional ao estratégico. 14.ed. São Paulo: Saraiva, 2011.

MEDEIROS, J.; SOUZA, W. A racionalidade na gestão do setor social: estudos em organizações de caráter solidário. Revista de Gestão, v. 18, n. 2, p. 145-158, 2011.

MOZZATO, A. R.; GRZYBOVSKI, D. Abordagem crítica nos Estudos Organizacionais: concepção de indivíduo sob a perspectiva emancipatória. Cadernos EBAPE.BR, v. 11, n. 4, p. 503-519, 2013.

MUÇOUÇAH, R. A. O. De empregados a colaboradores: a introjeção de valores individualistas como fator desarticulador dos sindicatos. Revista de Estudos Jurídicos, v. 17, n. 26, 2013. 
MUZZIO, H. A Condição paradoxal da administração de recursos humanos: entre a racionalidade instrumental e a racionalidade substantiva. Cadernos Ebape.BR, v. 12, n. 3, artigo 9, p. 706-718 jul./set. 2014.

OLTRAMARI, A. P.; FRIDERICHS, B. P.; GRZYBOVSKI, D. Carreira, família e a dialógica do assujeitamento: o discurso vigente em uma revista popular de negócios.

Cadernos EBAPE.BR, v. 12, n. 1, artigo 6, jan./mar, 2014.

PINTO, G. A. O Toyotismo e a mercantilização do trabalho na indústria automotiva do Brasil. Cadernos CRH, Salvador, v. 25, n. 66, p. 535-552, 2012.

POUTSMA, E.; LIGTHART, P. E. M.; VEERSMA, U. The diffusion of calculative and collaborative HRM practices in European firms. Industrial Relations, v. 45, n.4, p. 513-546, 2006.

ROCHA-DE-OLIVEIRA, S.; PICCININI, V. C.; BITENCOURT, B. M. Juventudes, gerações e trabalho: É possível falar em geração Y no Brasil? Organizações \& Sociedade, v. 19, n. 62, p. 551-558, 2012.

ROHM, R. J. D.; LOPES, N. F. O novo sentido do trabalho para o sujeito pós-moderno: uma abordagem crítica, Cadernos EBAPE.BR, v. 13, n. 2, p. 332 - 345, Abr./Jun. 2015.

ROSA, A.; ALCADIPANI, R. A terceira margem do rio dos estudos críticos sobre administração e organizações no Brasil: (re)pensando a crítica a partir do pós-colonialismo. Revista de Administração Mackenzie, v. 14, n. 6, Edição Especial, p. 185 -215, 2013.

ROSIM, D.; ESCRIVÃO FILHO, E.; NAGANO, M. S. O trabalho do dirigente da pequena empresa à luz da abordagem dos papéis de Mintzberg: insights em empresas brasileiras.

Revista de Empreendedorismo e Gestão de Pequenas Empresas, v. 8, n. 2, p. 365-391, abr. 2019.

SOUTO-MAIOR, J. Racionalidades: alguns esclarecimentos. Estudos Avançados em Administração, v. 6, n. 2, p. 967-991, 1998.

VOGT, S.; BULGACOV, Y. L. M. História de vida de empreendedores: estratégia e método de pesquisa para estudar a aprendizagem empreendedora. Revista de Empreendedorismo e Gestão de Pequenas Empresas, v. 8, n. 3, p. 99-133, set. 2019.

WOOD JR., T. Fordismo, toyotismo e volvismo: os caminhos da indústria em busca do tempo perdido. Revista de Administração de Empresas, v. 32, n. 4, p. 6-18, set./out. 1992.

ZARIFIAN, P. Engajamento subjetivo, disciplina e controle. Novos Estudos CEBRAP, São Paulo, n. 64, p. 23-31, 2002. 